\title{
Prevalence of Occupational Health Hazards and Safety Measures Among Municipal Waste Workers at Assiut city
}

\author{
Shimaa Mohamed Zaky ${ }^{1}$, Neama Mohamed El- Magrabi ${ }^{2}$ \& Fayza Mohammed Mohammed ${ }^{3}$. \\ 1. Teaching Specialist of Nursing Sciences in Technical of Health Institute in Assiut \\ 2. Assistant Professor of Community Health Nursing, Faculty of Nursing, Assiut University, Egypt. \\ 3. Lecturer of Community Health Nursing, Faculty of Nursing, Assuit University, Egypt
}

\begin{abstract}
Municipal Waste Workers in waste management operations are the primary affected population at risk of exposure to waste hazards. This study aimed to: Assess the prevalence of occupational health hazards and safety measure among Municipal waste workers at Assiut city. Subjects \&Methods: Descriptive research design was utilized. The convenience sampling was used; the total number (400) workers. Data were collected by utilizing two tools; First tool: Demographic questionnaire Sheet Second tool: An Observational Check List for practice of municipal waste workers. Results: Presented that $40.5 \%$ of the workers aged more than 50 years, while $27.0 \%$ less than 40 years. Also $70.7 \%$ of the workers were exposure to injury during work. While $93.7 \%$ of workers don't use personal safety measures. Only $25.25 \%$ of the studied sample had good knowledge. Conclusion: More than one third of the workers had poor knowledge about occupational health hazards and not applies safety measures practice. Recommendations: Educational program for workers to improve their knowledge and practice about occupational hazards and personal protective equipment.
\end{abstract}

Keywords: Municipal Waste Workers, Occupational Health Hazards\& Personal Protective Equipment.

\section{Introduction}

Municipal waste management is a livelihood to poor people of low educational levels, inadequate housing conditions in rural residence, large family size with insufficient family income. In Egypt, this job is mainly and formally performed by male employees and the same applies in other countries. Workers involved in waste collection, sorting, treatment and landfill and thus directly exposed to solid waste had lower socio-economic standard, lower educational level and resided rural areas where life conditions lags behind urban community (Abd El-Wahab et al., 2014).

Municipal waste (MW) is produced mainly by households, although there are similar wastes from sources such as trade, offices and public institutions. The amount of municipal waste resulting from waste collected by or on behalf of the municipal authorities is disposed of through the waste management system (Eurostat, 2012).

The waste management includes traditional services such as collecting waste from households, public spaces, and businesses, and then transporting them to recycling, incineration, or landfill. The waste management services have multiple areas: collection and transportation of waste materials; treatment of waste materials; recycling; cleaning business facilities, and industrial supplies (Byung et al., 2016).

Waste pikers play an important role in maintaining the health and hygiene in the cities. This job exposes municipal waste workers to a variety of risk factors such as dust, volatile organic matter and mechanical stress, which make them susceptible to certain occupational diseases, accidents, injuries, cuts and wounds, skin infections and animal bites (Gillett, 2012).

Waste handling is associated with various adverse effects because of the way and manner by which waste collectors perform their duty with its perceived negative health impacts associated with improper handling of such waste. The responsibilities of solid waste collectors include emptying of refuse containers into a truck using either hydraulic lift or their physical strength and describing the criterions for appropriate disposal to customers (Sani \& Puziah, 2014).

Preventive measures, it refers to protective devices commonly used such as gloves, masks, handkerchief, helmet, earplugs, wear of safety belts also hygienic practices while consuming food and water, (Owen $\&$ Scott,2018).

Occupational health nurse is the professional and specialized practices that provide health and safety programs and services to workers and community groups. This practice focuses on health promotion and recovery, disease and injury prevention, and protection against occupational environmental hazards (AAOHN, 2013).

The training of workers on occupational health and safety issues, as well as workers' rights within the work place has been an important part of improving working conditions. Workers prior to commencement 
of new assignments should receive adequate training and information enabling them to understand the hazards of work and to protect their health from ambient factors that may present. The training must cover knowledge of materials, equipment s and tools; known hazards in the operations and how to control these hazards; potential risks to health; hygiene requirements; wearing and use of PPE; and appropriate extremes, incidents and accidents (Fikrom et al., 2016).

\section{Significance of the study}

The overall prevalence of respiratory symptoms among solid waste collectors in Yeka sub city was $40.7 \%$ with prevalence of cough $35.7 \%$, wheezing $21.2 \%$, phlegm $44 \%$, chest illness $7.3 \%$ and breathlessness $29.2 \%$ (Zerihun et al., 2017).

In the study carried out by (Abd El-Wahab et al., 2014) in Alexandria, They reported that history of work related accident $79.2 \%, \operatorname{cough}(29.1 \%)$, fatigue (27.5\%), attacks of abdominal colic (25.5\%) , diarrhea $(24.5 \%)$,dyspepsia $(24.3 \%)$, headache $(21.1 \%))$, low back pain , sciatic pain constituted $17.3 \%$ and vomiting, or dysentery were reported by $(10.9 \%)$.

No studies have been conducted at Assiut regarding exposure and health effects among municipal waste workers, therefore this study was selected.

\section{Aim of the study}

*To identify the prevalence of occupational health hazards and safety measures among municipal waste workers at Assiut city.

\section{Research questions}

1- Are municipal wastes workers have knowledge about hazards of waste collection and safety measures practice?

2- What is the prevalence of occupational health hazards among municipal waste workers?

\section{Subjects \& Methods}

Research design: Descriptive study design was used in this research.

Setting: The present study was conducted in two different sectors at Assiut city namely East and West district.

\section{Sample and Sampling}

All workers at Assiut city were 400 workers, 230 Municipal waste workers (MWW) at East sectors of Assiut, and 170 MWWs at West sectors at Assiut City and it was a convenient sample.

Tools of data collection

After reviewing the relevant literature, two proper tools were used for collection of data:

Tool I: A structured Interview questionnaire Sheet.
It was developed by the researchers to collect information from the study sample. It was written in Arabic language and divided in to three parts

Part 1: Demographic Characteristics of the MWWs, which include age, marital status, educational level, and personal habits as smoking, training program, injury history as injury during work, type sand site of injuries and referral.

Part 2: Knowledge of the MWWs about occupational health hazards which include:-Types of hazard exposure, it consists of 4 questions physical hazards, chemical hazards, biological hazards and accident. Causes of health hazards it consists of 9 questions about old equipment, lack of certain equipment, absence of periodic maintenance of equipment, unavailability of work tools, non-compliance with protective clothes, dealing with waste incorrectly, neglecting personal hygiene, lack of attention in his work, non-compliance by using protective clothes.

Part 3: Knowledge of the municipal waste workers about protection from exposure to health hazards in the work it consists of 6 questions about vaccination, compliance with personal hygiene, wear protective clothes, avoid smoking while working and avoid eating foods during work time, using protective equipment.

\section{The Scoring System}

1-knowledge score: For knowledge elements, a correct response take 1 grade $\&$ zero grades for incorrect response recorded. The grades of each correct item summed -up and converted into percent score. Poor score $<\mathbf{6 0} \%$. Average score was 60- $70 \%$. Good score $>70 \%$. Awad (2014).

Tool (II): An Observational Check List, which was developed from Reinhold (2000) and modified by the researchers where some items not available for us such as outfit visible signs. The municipal waste workers practices regarding the personal protective equipment; it consists of 10 items as using of normal overall, head cap, using of masks, using of gloves, using of rubber shoes, change wear at the beginning of the shift, change wear at the end of the shift, hand washing, washing face and wash the feet.

\section{The Scoring System}

2-Practice score: for utilization of personal protective equipment, 1 grade for a correct response $\&$ zero grade for incorrect response. All grades of each correct item summed -up and converted into percent score. Not done score was $<50 \%$. Done score was $\geq \mathbf{5 0 \%}$.

\section{Methodology}

Preparatory phase: The tools were developed after reviewing the relevant international literature in various aspects of the problem using different books, articles and studies, and then presented the tools to experts for review and validation. 
Validity: These tools were reviewed by five experts in community health nursing at Assiut University

Reliability: to evaluate the sheet reliability was analyzed by Cronbach's Alpha to measure reliability about Knowledge 0.85 and also practices were 0.87 which were accepted.

Pilot Study: It includes $10 \%$ of the studied sample (40) workers who were excluded from the study. The aim of pilot study to evaluated the clarity, of the tools. It also helped in the estimation of the time needed to fill the forms.

Field work: Data was collected in the period from the beginning of December 2015, until the end of May 2016.The researchers interviewed each person individually according to his work circumstances to obtain the necessary information after introduced and explained the purpose of study. The average time taken to complete their self each interview was around 15- 20 minutes depending on the person's response to questions. Observation checklist was done by the researchers themself, it took from 1520 minutes .All of these activities done at the work places 3days/week, the number of persons ranged from 4-5 person / day.

\section{Ethical consideration}

An official approval was obtained from the community nursing department counsels \& the scientific research ethics committee those were approved by the Faculty of Nursing, Assuit University Counsel. The aim of the study was explained to each municipal waste worker before applying the tools to gain his confidentially and trust. An oral consent was obtained from each worker to participate in the study, after ensuring that data collected will be treated confidentially.

\section{Statistical analysis}

Data entry and data analysis were done using SPSS version 19 (Statistical Package for Social Science). Data were presented as number and percentage. Chisquare test was used to compare between qualitative variables. Pearson correlation was done to measure correlation between quantitative variables. P-value considered statistically significant when $\mathrm{P}<0.05$. 


\section{Results}

Table (1): Distribution of the studied sample regarding to their socio-demographic characteristics at Assiut city, $2016(\mathrm{No}=400)$.

\begin{tabular}{|l|c|c|}
\hline \multicolumn{1}{|c|}{ Demographic } & No & \% \\
\hline Age: & & 27.0 \\
\hline$<40$ years & 108 & 32.5 \\
\hline $40-50$ years & 130 & 40.5 \\
\hline$>50$ years & 162 & 70.2 \\
\hline Education: & 281 & 18.8 \\
\hline Illiterate & 75 & 5.0 \\
\hline Read \& write & 20 & 6.0 \\
\hline Basic education & 24 & \\
\hline Secondary education & & 4.2 \\
\hline Marital status: & 17 & 95.8 \\
\hline Single & 383 & 8.8 \\
\hline Married & & 91.2 \\
\hline Job: & 35 & \\
\hline Waste collector & 365 & 23.2 \\
\hline Street sweepers & & 29.3 \\
\hline Years of experience: & 93 & 20.0 \\
\hline$<10$ years & 117 & 27.5 \\
\hline $10-<15$ & 80 & \\
\hline $15-<20$ & 110 & 62.0 \\
\hline$\geq 20$ & & 38.0 \\
\hline Smoking: & 248 & \\
\hline Smoker & 152 & 6.5 \\
\hline Non-smoker & & 21.8 \\
\hline Cause of smoking $(\mathbf{n}=\mathbf{2 4 8}):-$ & 16 & 58.0 \\
\hline Boredom & 54 & \\
\hline Without causes & 34 & \\
\hline Habituation & 144 & \\
\hline odor and tiring job & & \\
\hline Training Program $(\mathbf{n}=\mathbf{4 0 0})$ & & \\
\hline Yes & & \\
\hline No & & \\
\hline & & \\
\hline & & \\
\hline
\end{tabular}

Table (2): Distribution of the studied sample regarding to their history of injury at Assiut city, 2016(No= 400).

\begin{tabular}{|l|c|c|}
\hline \multicolumn{1}{|c|}{ History of injury } & No & \% \\
\hline Injury during work & & 70.7 \\
\hline Yes & 283 & \\
\hline Types of injury (n=283) & & 47.7 \\
\hline Wounds & 135 & 25.4 \\
\hline Motor car accident & 72 & 24.7 \\
\hline Fall from height & 70 & 2.1 \\
\hline Fractures & 6 & \\
\hline Site of injury $(\mathbf{n}=283)$ & & 54.1 \\
\hline Lower limbs & 153 & 43.5 \\
\hline Upper limbs & 123 & 8.1 \\
\hline Face & 23 & 5.7 \\
\hline Others* & 16 & 4.2 \\
\hline Skull & 12 & \\
\hline
\end{tabular}




\begin{tabular}{|l|c|c|}
\hline \multicolumn{1}{|c|}{ History of injury } & No & \% \\
\hline Vertebral column & 11 & 3.9 \\
\hline Chest & 4 & 1.4 \\
\hline Referral: $(\mathbf{n}=283)$ & & 76.7 \\
\hline Yes & 217 & 23.3 \\
\hline No & 66 & \\
\hline
\end{tabular}

- More than answer others*e.g. bladder, loss of teeth, pelvic fissure, contusions

Table (3): Distribution of the studied sample regarding to their knowledge about exposure to health hazards in work place at Assiut city, 2016 $(\mathrm{No}=400)$.

\begin{tabular}{|c|c|c|}
\hline Knowledge & No (yes) & $\%$ \\
\hline $\begin{array}{l}\text { Physical hazards : } \\
\text { Natural hazards such as } \\
\text { - Heat stroke. } \\
\text { - Cold weather. } \\
\text { - noise }\end{array}$ & $\begin{array}{c}(335) \\
110 \\
90 \\
135\end{array}$ & 83.8 \\
\hline $\begin{array}{l}\text { Chemical hazards:- } \\
\text { Burns by } \\
\text { - powders } \\
\text { - } \quad \text { electric stun }\end{array}$ & $\begin{array}{c}(216) \\
190 \\
26\end{array}$ & 54.0 \\
\hline $\begin{array}{l}\text { Biological hazards:- } \\
\text { Twitching through contaminated syringes and other tree thorns } \\
\text { Wounds with broken glass and other sharp objects. } \\
\text { Infection through exposure to dust- insects and diapers }\end{array}$ & $\begin{array}{c}158 \\
159 \\
149 \\
\end{array}$ & $\begin{array}{l}39.5 \\
39.8 \\
37.3 \\
\end{array}$ \\
\hline $\begin{array}{l}\text { Accidents hazards :- } \\
\text { Slipping and falling from truck }\end{array}$ & 162 & 40.5 \\
\hline
\end{tabular}

-More than one answer

Table (4): Distribution of the studied sample regarding to their knowledge about Causes of health hazards in work place at Assiut city, $2016(\mathrm{No}=400)$.

\begin{tabular}{|l|c|c|}
\hline \multicolumn{1}{|c|}{ Causes } & No (yes) & $\%$ \\
\hline \hline Old equipment's & 367 & 91.8 \\
\hline Lack of certain equipment & 364 & 91.0 \\
\hline Absence of periodic maintenance & 351 & 87.8 \\
\hline Un availability of work tools & 258 & 64.5 \\
\hline Non-compliance with protective clothes & 226 & 56.5 \\
\hline Dealing with waste incorrectly & 198 & 49.5 \\
\hline Neglecting personal hygiene & 196 & 49.0 \\
\hline Lack of attention in the work & 174 & 43.5 \\
\hline Non-compliance by using protective clothes & 112 & 28.0 \\
\hline
\end{tabular}

Table (5): Distribution of the studied sample regarding to their knowledge about protective items from exposures to health hazards in the work place at Assiut city, 2016(No= 400).

\begin{tabular}{|l|c|c|}
\hline \multicolumn{1}{|c|}{ Protective items } & No (yes) & \% \\
\hline Immunization (vaccinations) & 315 & 78.8 \\
\hline Compliance with personal hygiene & 271 & 67.8 \\
\hline Wear protective clothes & 265 & 66.3 \\
\hline Avoid eating during work time & 239 & 59.8 \\
\hline Avoid smoking during working & 152 & 38.0 \\
\hline Using equipment & 103 & 25.8 \\
\hline
\end{tabular}

More than one answer 
Table (6): Distribution of the studied sample regarding to their practice about preventive measures in the work place at Assiut city, $2016(\mathrm{No}=400)$.

\begin{tabular}{|l|c|c|}
\hline \multicolumn{1}{|c|}{ Practice } & No (done) & \% \\
\hline Change wear at the beginning of the shift & 284 & 71.0 \\
\hline Change wear at the end of the shift & 276 & 69.0 \\
\hline Hand washing & 148 & 37.0 \\
\hline Washing face & 146 & 36.5 \\
\hline Wash the feet & 96 & 24.0 \\
\hline Costume (suit-normal overall) & 60 & 15.0 \\
\hline Rubber shoes (BOT) & 59 & 14.8 \\
\hline
\end{tabular}

- More than one practice.

- Notes: All the studied workers not wear protective clothes as head cap, gloves and mask.

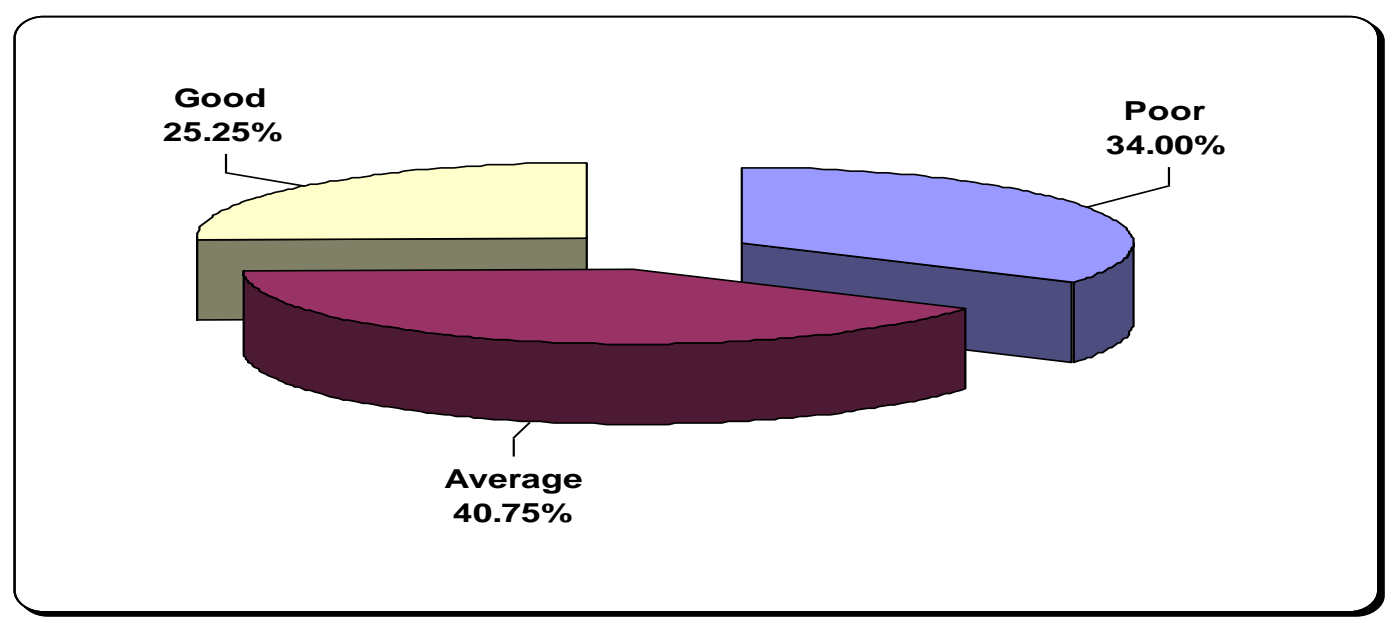

Figure (1): distribution of studied workers' total score knowledge regarding to causes of occupational hazards during work at Assuit city, 2016.

Table (7): Relationship between the total score of knowledge between the studied workers and their personal demographic characteristics at Assiut City, 2016.

\begin{tabular}{|c|c|c|c|c|c|c|c|c|}
\hline \multirow{3}{*}{$\begin{array}{c}\text { personal demographic } \\
\text { characteristics }\end{array}$} & \multirow{3}{*}{ Total } & \multicolumn{6}{|c|}{ Level of knowledge } & \multirow{3}{*}{ P-value } \\
\hline & & \multicolumn{2}{|c|}{ Poor } & \multicolumn{2}{|c|}{ Satisfactory } & \multicolumn{2}{|c|}{ Good } & \\
\hline & & No. & $\%$ & No. & $\%$ & No. & $\%$ & \\
\hline Age: & & & & & & & & \multirow{4}{*}{$0.008 *$} \\
\hline$<40$ years & 108 & 29 & 26.9 & 43 & 39.8 & 36 & 33.3 & \\
\hline 40 - 50 years & 130 & 45 & 34.6 & 46 & 35.4 & 39 & 30.0 & \\
\hline$>50$ years & 162 & 62 & 38.3 & 74 & 45.7 & 26 & 16.0 & \\
\hline \multicolumn{8}{|l|}{ Education: } & \multirow{3}{*}{$0.000 *$} \\
\hline Un educated & 281 & 132 & 47.0 & 142 & 50.5 & 7 & 2.5 & \\
\hline Educated & 119 & 4 & 3.4 & 21 & 17.6 & 94 & 79.0 & \\
\hline \multicolumn{8}{|l|}{ Marital status: } & \multirow{3}{*}{0.890} \\
\hline Single & 17 & 5 & 29.4 & 7 & 41.2 & 5 & 29.4 & \\
\hline Married & 383 & 131 & 34.2 & 156 & 40.7 & 96 & 25.1 & \\
\hline \multicolumn{8}{|l|}{ Job: } & \multirow{3}{*}{$0.008 *$} \\
\hline Waste collector & 35 & 4 & 11.4 & 17 & 48.6 & 14 & 40.0 & \\
\hline Street sweepers & 365 & 132 & 36.2 & 146 & 40.0 & 87 & 23.8 & \\
\hline \multicolumn{8}{|l|}{ Years of experience: } & \multirow{5}{*}{$0.021 *$} \\
\hline$<10$ years & 93 & 32 & 34.4 & 35 & 37.6 & 26 & 28.0 & \\
\hline $10-<15$ & 117 & 33 & 28.2 & 44 & 37.6 & 40 & 34.2 & \\
\hline $15-<20$ & 80 & 24 & 30.0 & 42 & 52.5 & 14 & 17.5 & \\
\hline$\geq 20$ & 110 & 47 & 42.7 & 42 & 38.2 & 21 & 19.1 & \\
\hline
\end{tabular}




\begin{tabular}{|c|c|c|c|c|c|c|c|c|}
\hline \multirow{3}{*}{$\begin{array}{l}\text { personal demographic } \\
\text { characteristics }\end{array}$} & \multirow{3}{*}{ Total } & \multicolumn{6}{|c|}{ Level of knowledge } & \multirow{3}{*}{ P-value } \\
\hline & & \multicolumn{2}{|c|}{ Poor } & \multicolumn{2}{|c|}{ Satisfactory } & \multicolumn{2}{|c|}{ Good } & \\
\hline & & No. & $\%$ & No. & $\%$ & No. & $\%$ & \\
\hline \multicolumn{8}{|l|}{ Smoking: } & \multirow{3}{*}{0.671} \\
\hline Smoker & 248 & 87 & 35.1 & 102 & 41.1 & 59 & 23.8 & \\
\hline Non-smoker & 152 & 49 & 32.2 & 61 & 40.1 & 42 & 27.6 & \\
\hline
\end{tabular}

* Statically Significant. $(p \leq 0.05)$.

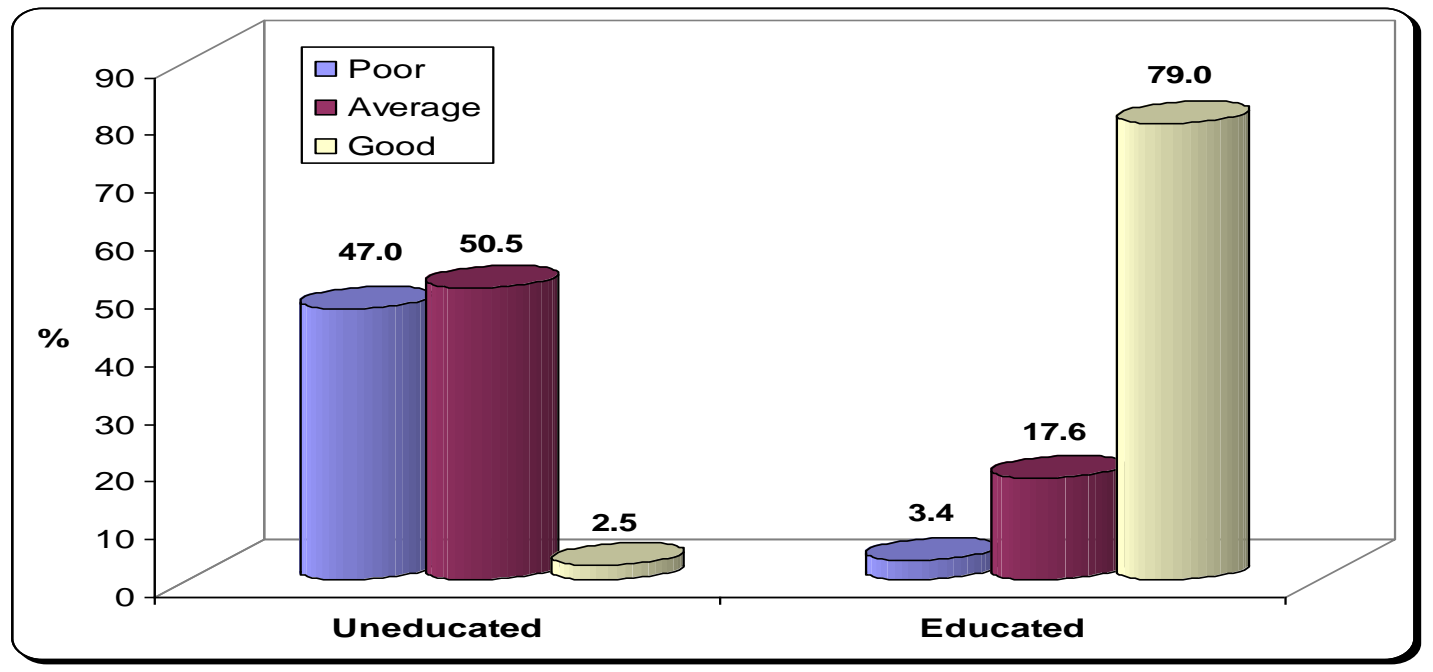

Figure (2): Relation between studied workers' education and their level of Knowledge about occupational health hazards in work place at Assiut City, 2016.

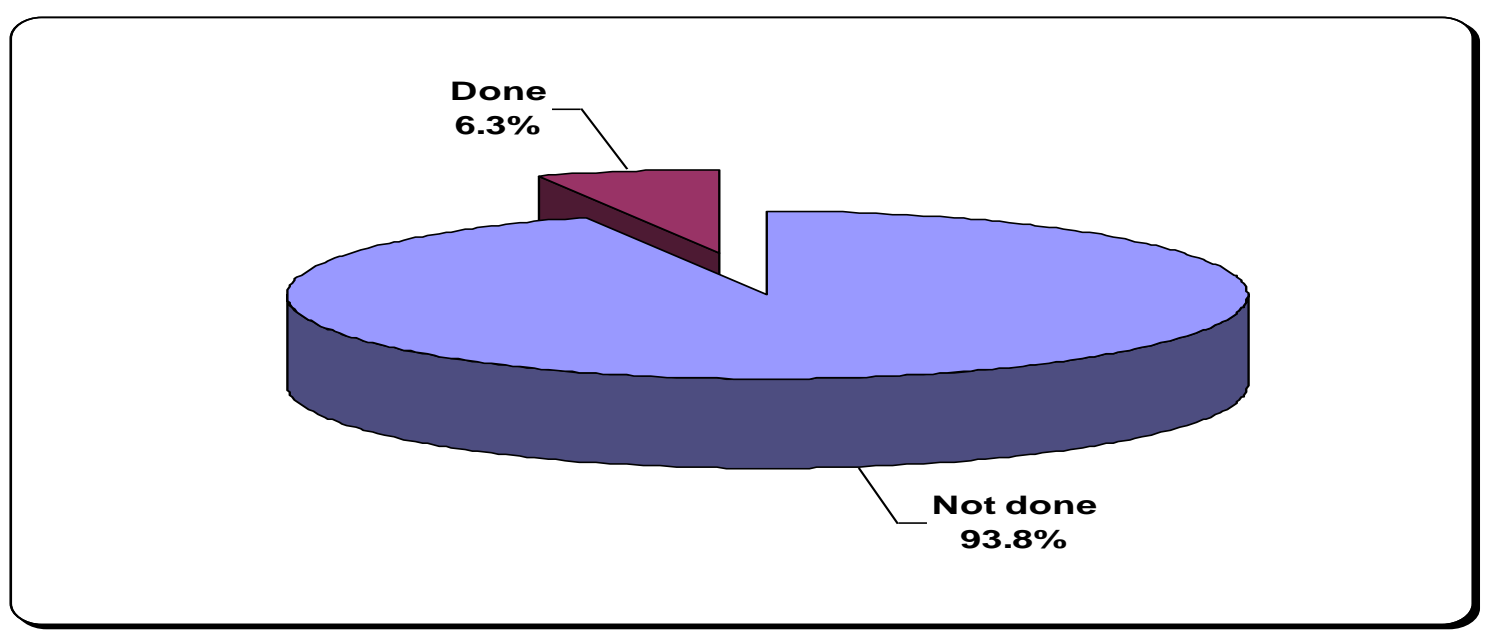

Figure (3): The total score of the studied sample about level of practice in work place at Assiut city, 2016.

Table (8): Relationship between studied workers' level of practice and their demographic characteristics at Assiut city, 2016.

\begin{tabular}{|c|c|c|c|c|c|c|}
\hline \multirow{3}{*}{ Items } & \multirow{3}{*}{ Total } & \multicolumn{4}{|c|}{ Level of performance } & \multirow{3}{*}{ P-value } \\
\hline & & \multicolumn{2}{|c|}{ Inadequate } & \multicolumn{2}{|c|}{ Adequate } & \\
\hline & & No. & $\%$ & No. & $\%$ & \\
\hline \multicolumn{6}{|l|}{ Age: } & \multirow{4}{*}{0.320} \\
\hline$<40$ years & 108 & 104 & 96.3 & 4 & 3.7 & \\
\hline $40-50$ years & 130 & 119 & 91.5 & 11 & 8.5 & \\
\hline$>50$ years & 162 & 152 & 93.8 & 10 & 6.2 & \\
\hline
\end{tabular}




\begin{tabular}{|c|c|c|c|c|c|c|}
\hline \multirow{3}{*}{ Items } & \multirow{3}{*}{ Total } & \multicolumn{4}{|c|}{ Level of performance } & \multirow{3}{*}{ P-value } \\
\hline & & \multicolumn{2}{|c|}{ Inadequate } & \multicolumn{2}{|c|}{ Adequate } & \\
\hline & & No. & $\%$ & No. & $\%$ & \\
\hline \multicolumn{6}{|l|}{ Education: } & \multirow{3}{*}{0.107} \\
\hline Un educated & 281 & 267 & 95.0 & 14 & 5.0 & \\
\hline Educated & 119 & 108 & 90.8 & 11 & 9.2 & \\
\hline \multicolumn{6}{|l|}{ Marital status: } & \multirow{3}{*}{0.614} \\
\hline Single & 17 & 17 & 100.0 & 0 & 0.0 & \\
\hline Married & 383 & 358 & 93.5 & 25 & 6.5 & \\
\hline \multicolumn{6}{|l|}{ Job: } & \multirow{3}{*}{0.712} \\
\hline Waste collector & 35 & 34 & 97.1 & 1 & 2.9 & \\
\hline Street sweepers & 365 & 341 & 93.4 & 24 & 6.6 & \\
\hline \multicolumn{6}{|l|}{ Years of experience: } & \multirow{5}{*}{$0.019 *$} \\
\hline$<10$ years & 93 & 88 & 94.6 & 5 & 5.4 & \\
\hline $10-<15$ years & 117 & 113 & 96.6 & 4 & 3.4 & \\
\hline $15-<20$ years & 80 & 69 & 86.3 & 11 & 13.8 & \\
\hline$\geq 20$ years & 110 & 105 & 95.5 & 5 & 4.5 & \\
\hline \multicolumn{6}{|l|}{ Smoking: } & \multirow{3}{*}{0.832} \\
\hline Smoker & 248 & 233 & 94.0 & 15 & 6.0 & \\
\hline Non-smoker & 152 & 142 & 93.4 & 10 & 6.6 & \\
\hline
\end{tabular}

$*$ Statically Significant $(p \leq 0.05)$.

Table (1): Shown distribution of studied sample according to their personal characteristics it was cleared that $40.5 \%$ of the workers aged more than 50 years, $27.0 \%$ less than 40 years. As regard to their level of education, $70.2 \%$ illiterate. While $29.3 \%$ of workers (had job experience between 10 years and less than 15 years and $58.0 \%$ of the studied workers were smoking because of odors and tiring job. Table (2); illustrated that distribution of the studied sample regarding to history of injury it was cleared that $70.7 \%$ exposed to injury during work. $47.7 \%$ of the workers had wounds, followed by $25.4 \%$ exposed to motor car accident. $54.1 \%$ of them had injury in lower limbs, $43.5 \%$ of them had injury in upper limbs and only $1.4 \%$ of them had Chest injury. $22.4 \%$ have not been referred.

Table (3): Revealed that distribution of studied sample regarding to their knowledge about exposure to health hazards, only $37.3 \%$ of the studied workers had knowledge about biological hazards as infection. As regarded to distribution of the studied sample knowledge about Causes of health hazards in work place.

Table (4): revealed that, $91.8 \%$ of them had knowledge that old equipment are the causes and only $28.0 \%$ of the studied workers reported that Noncompliance by using protective clothes as a cause of health hazards in the work place.

Table (5): illustrated that distribution of the studied sample according to their knowledge about protective items from exposures to health hazards in the work place; it was revealed that $78.8 \%$ had knowledge about Immunization (vaccinations) and $25.8 \%$ of the studied workers had knowledge about using equipment.

Table (6) Regarding to studied sample practice of safety measures in the work place shows that there are all the studied workers not wear protective clothes as head cap, gloves and mask. $71.0 \%$ Change wear at the beginning of the shift.

Figure (1): Showed that only $25.25 \%$ of the studied workers had good knowledge.

Table (7): Revealed that relation between total score knowledge among studied workers according to their socio demographic characteristics, it shown that there is statistical significant difference between knowledge of workers and their age, level of education, job and years of experience at P-value $(0.008,0.000,0.008$ and 0.021$)$ respectively.

Figure (2): Revealed that $50.0 \%$ of uneducated studied workers had average level of knowledge about occupational health hazards, while 79.0 of the educated studied workers had good knowledge about occupational health hazards.

Figure (3): Revealed that; $93.8 \%$ of the studied workers have not done of practice, while only $6.3 \%$ of them done practice at work place.

Table (8): Regarding to relation between studied workers' performance and their demographic characteristics there is statistical significant difference between level of practice and Years of experience at P-value (0.019). 


\section{Discussion}

This study aimed to identify the prevalence of occupational health hazards and safety measure among Municipal waste workers at Assiut city. It's findings that around two fifth of the workers aged more than 50 years, these result agree with study about Exposure, Protection and Self-reported Health Problems Among Solid Waste Handlers in a Coastal Peri-urban community in Ghana which conducted by James et al., (2015)Who found that the age of the workers ranged from $40 \geq 60$. This finding disagree with study by Sani $\&$ Puziah, (2014) who conducted a study in Malaysia about Possible Health Danger Associated with Garbage /Refuse Collectors, the results show that the workers age range from 15 to 35 years.

According to the level of education the result of the current study revealed that more than two thirds of the studied workers were illiterate. These results agree with study by Abou-El Wafa et al., (2014) who conducted a study about musculoskeletal disorders Among Municipal Solid Waste Collectors in Mansoura, Egypt, the results show that the vast majority of the MSW collectors were illiterate.

This finding disagree with study by Mohd Shah \& Haliza, (2015) in a study carried out in Malaysia about Health Risk Survey for Domestic Waste Management, and show that more than two third of workers were pass secondary school education. This finding could be attributed due to that more of the studied subjects from rural areas and low economic status for workers.

Concerning years of experience of the studied workers, the current study showed that less than one third of workers had job experience between $10 \geq 15$ years, these result agree with study by Alan \& Philip, (2011) who carried out a study about Occupational Safety and Health Problems of Workers in Hong Kong, the results showed that more than half of the interviewees worked $6 \geq 10$ years.

The result was contrast with study by Daniel et al., (2014) who carried out a study about Assessment of Occupational Injuries among Addis Ababa city Municipal Solid Waste Collectors, the results showed that more than half of the workers have experience of $\leq 5$ years.

According to the causes of smoking between workers, the current study showed that more than half of the studied workers were smoking because of odor and tiring job, these result agree with study by Luigi et al., (2016) in a study about Assessment of Respiratory Health in Waste Collection and Disposal Workers in Bari, Italy, who showed that more than half of the studied workers were smoking because of odor and tiring job.
The current study was disagree with study by Debassu et al., (2016) in a study about Prevalence and Associated Factors of Occupational Injuries Among Municipal Solid Waste Collectors in four zones of Amhara region, Northwest Ethiopia, which reflect that just only $3.7 \%$ of workers were smokers . According to history of injury, the present study revealed that more than two thirds of the studied worker exposed to injury during works. This finding agrees with study by Pradeep \& Dhananjay, (2016) in a study about occupational morbidity among Municipal Solid Waste loaders in Mumbai, the results show that the vast majority of the workers exposure to injury during work. This can be attributed to poor condition of working environment as, noise, overcrowded, dark and slip of floor. The current study findings were in disagreement with study by Daniel et al., (2014) which reflect that more than two fifth of the workers exposure to injury during works.

The current study findings revealed that slightly less than half of the studied workers had wounds, this finding agree with study by Daniel et al., (2014) who notice that, more than half of the studied workers had wounds. Also, the findings present study of were agreed with Pradeep \& Dhananjay, (2016) who reflected that more than two thirds of the studied workers had wounds.

As regard to the distribution of injury in body parts at work place the current study revealed that more than half of the studied workers had injury in lower limbs and more than two fifth of them had injury in upper limbs. The present study agree with study by Daniel et al., (2014) who mentioned that more than one third of the studied workers had injury in lower limbs and two thirds of them had injury in upper limb. This finding could be attributed due to the poor design for the work of waste collectors that may contain work load above shoulder and walking for a long time in the traffic zones.

The current study incompatible with study by Byung et al., (2016) in a study carried out on Workplace Accidents and Work-related Illnesses of Household Waste Collectors Seoul, Republic of Korea, the result showed that around one quarter of the studied workers had injury in lower limbs and less than one fifth of them had injury in upper limbs.

According to workers' knowledge regarding exposure to health hazards, the current study represented that; more than one third of the studied workers had knowledge about infection which they exposure to it during the work. The present study agree with study by, James et al., (2015) which reflected that around two thirds of the studied workers had knowledge about infection which they exposure to it during the work. 
Regarding workers' knowledge about Causes of health hazards in the work place, the result of the present study cleared that the vast majority of the studied workers had knowledge that old equipment is the main cause for health hazards in work place while only more than one quarter of the workers knew that non-compliance by using equipment is a cause of health hazards. The present study result was in the same line with study done by Debassu et al., (2016) which reflected that more than two thirds of the workers had knowledge that old equipment is the cause.

The current study findings revealed that more than one quarter of the studied workers had knowledge about using equipment. The present study results were in the same line with study by, Naiara et al., (2013) in a study about Profile Survey of Waste Pickers in Brazile: Requirements for the Development of a Collection Vehicle and Optimized Routing, reported that, one quarter of the studied workers had knowledge about using equipment. This finding could be attributed due to that there is not educational program for the workers about items that protect them during the work.

The present results were disagree with study done by, Zemichael et al., (2014) about Assessment of Occupational Injury and Associated Factors Among Municipal Solid Waste Workers in Gondar town and Bahir Dar City, Northwest Ethiopia, which reflected that about two-thirds of workers had knowledge about using equipment.

As regard to practice about personal protective equipment by workers in the work place, the present study show that there is no one of the study workers compliance with protective clothes as wearing gloves, mask and more than two thirds of them change clothes at the beginning of the shift. This result was in the same line with study by Mostafa et al., (2015) which reflected that there is no one of the study workers wearing face mask. This finding could be attributed to that municipal waste workers preferred working without wearing gloves, as these limited their free movement during work.

These results in contrast with study by Abd ElWahab et al., (2014) which reflected that about two thirds of the study workers wear the overall, about one third wearing head cap and more than quarter of the study workers wearing gloves.

As shown by the present study findings that more than one third of the studied workers had poor knowledge. The current study findings were in accordance with Awad, (2014) who cleared that half of the workers had poor knowledge. This finding could be attributed to more than two thirds of the workers are illiterate.
According to relation between workers' knowledge \& years of experience, it was noticed that there were significant difference between knowledge \& years of experience and occupational health hazards. The current study findings were in accordance with Ewis et al., (2013) who mentioned that were significance difference. This can be explained by the fact that workers gain knowledge through their job.

Concerning the relation between studied workers' practice and their demographic characteristics at Assiut city the present study showed that; there is statistical significant difference between level of performance and Years of experience at P-value (0.019).This result were in the same line with study by James et al., (2015) who cleared that were significance difference between level of performance and Years of experience. This result in contrast with study by Daniel et al., (2014) who reported that where were no significance difference between level of performance and Years of experience.

\section{Conclusion}

Based on the results of the present study, it can be concluded that

More than two thirds of municipal waste workers have been exposed to injury during work. The vast majority of municipal waste workers suffer from musculoskeletal system complain. Slightly more than one quarter of them had good knowledge about occupational health hazards. The vast majority of municipal wastes workers not apply of preventive measures. There were significant in knowledge \& years of experience\& level of education and occupational health hazards.

\section{Recommendation}

Based on the results of present study it can be recommended that

1-Provide health education \& training programs should be carried out regularly, special for occupational hazards and preventive measures for workers.

2-Immunization and Periodic medical examination should be performed to all municipal waste workers.

3-Further research is recommended to investigate sustainable preventive strategies to control and reduce exposure to occupational health hazards among (MWW).

4-Aguidline book should be distributed to (MWW) for prevention of occupational health hazards.

\section{References}

1. Abd El-Wahab E., Safaa M., Sameh E., Sanaa A., Hanan Z., \& Amira M., (2014): Adverse Health Problems Among Municipality Workers in 
Alexandria (Egypt) Int J Prev Med ; vol 5(5), pp:545-556.

2. Abou-ElWafa H., El-Bestar S., El-Gilany A., \& Awad E., (2015): Musculoskeletal disorders among municipal solid waste collectors in Mansoura, Egypt: a cross-sectional study. . BMJ Open; 2(5), pp: 32-65.

3. Alan H., \& Philip C., (2011): Occupational Safety and Health Problems of Workers in Hong Kong Recycling Industries - A Preliminary Ergonomic Study.vol 3(11), pp: 1320-1345.

4. American Association of Occupational Health Nurses, (2013): Occupational health nurses' roles.vol 68, pp: 1243-1255. (http://www.osha.gov/dts/oohn/ohn.html).

5. Anwar S., Mehmood N., Nasim N., Khurshid M., \& Khurshid B., (2013): Sweepers lung disease: a cross-sectional study of an overlooked illness among sweepers of Pakistan. International Journal of Chronic Obstructive Pulmonary Disease, vol 8(3) pp: 193-197.

6. Awad H., (2014): Occupational Hazards and Preventive Measures among Waste Collection Workerslin Cairo Egypt.pp:33-35, Available 'at www.eulc.edu.eg/eulc_v5/Libraries/.../Brows

7. Byung J., Sangbok L., \& Jae D., (2016): Workplace Accidents and Work-related Illnesses of Household Waste Collectors .Original Research Article Safety and Health at Work, Volume 7, (2), Pp: 138-142.

8. Daniel B., Abera K., \& Worku T., (2014): Assessment of occupational injuries among Addis Ababa city municipal solid waste collectors: a cross-sectional study. PMC.vol 9 pp: 110-130.

9. Debassu E., Zewdie A., Kedir Y., \& Fentaw T., (2016): Prevalence and associated factors of occupational injuries among municipal solid waste collectors in four zones of Amhara region, Northwest Ethiopia. Department of Industrial and Management Engineering, Hansung University, Seoul, Republic Safety and Health at Work ,vol 7(5) ,pp: 138-142.

10. Eurostat C., (2012): Managing municipal solid waste - European Environment Municipal waste search database), pp:120 available at (http://epp.eurostat.ec.europa.eu/portal/page/porta 1/statistics/..

11. Ewis A., Rahma M., Mohamed E., Hifnawy T., \& Arafa A., (2013): Occupational health related morbidities among street sweepers and waste collectors at beni- suef, Egypt. Egyptian Journal of Occupational Medicine, vol 37 (1): pp.79-94.

12.-Fikrom G., Mesfin Kote D., Abera K., Zemedu M., \& Andamlak G., (2016):
Assessment of Knowledge, Attitude and Practices Among Solid Waste Collectors in Lideta Sub-city on Prevention of Occupational Health Hazards, Addis Ababa, Ethiopia. Journal of Public Health Volume 4,(1), Pp: 49-56.

13. Gillett J., (2012): Municipal solid waste composting: Issue in risk assessment and management/Worker health and safety: MSW composting fact sheets. Institute for comparative and environmental toxicology at Cornell University. Biomass and Bioenergy; vol 3, pp: 145-162.

14. James-Paul K., Mawuli D., Thilde R., Irene A., Flemming K., Julius N., \& Anders D., (2015): Exposure, protection and self-reported health problems among solid waste handlers in a Coastal Peri-urban community in Ghana.vol 8, pp:225235.

15. Luigi V., Antonio B., Maria F., Luigi D., Antonio C., Angelica A., Francesco C., \& Raffaello M., (2016): Respiratory Health in Waste Collection and Disposal Workers. Int J Environ Res Public Health; vol 13(7): pp: 631654.

16. Mohd Shah H., \& Haliza A., (2015): Health Risk Survey for Domestic Waste Management Agency Workers: Case Study on Kota Bharu Municipal Council (MPKB), Kelantan, Malaysia International Journal of Environmental Science and Development, Vol. 6, (8).pp:55-88.

17. Mostafa S., Abdel-Hamid A., \& AlBagoury S., (2015): Work-related respiratory disorders among street sweepers in Cairo, Egypt, a comparative study. The Egyptian Journal of Community Medicine Vol. 33 ,(2).pp: 45-80.

18. Naiara F., Armando B., Fernando A., \& Odacir D., (2013): Profile survey of waste pickers in Brazil requirements for the development of a collection vehicle and optimized routing. Journal of Urban and Environmental Engineering (JUEE), v.7, (2) p. 231-246.

19. Owen, C., \& Scott, A., (2018): Textbook Fundamental of Mobil Heavy Equipment. $1^{\text {st }}$ ed. Pp.52.By Jones and Brtlett learning, LLC.USA.

20.Pradeep S., \& Dhananjay W., (2016): Occupational Morbidity among Municipal Solid Waste Loaders in Mumbai vol 24, pp: 165-187.

21. Reinhold R., (2000): An Observational Check List, Basic principale chick list: available at www.tropicalhealthsolutions.com/publicationslist rmuller.

22. Sani M., \& Puziah A., (2014): Possible Health Danger Associated With Gabbage/Refuse Collectors Selangor, Malaysia. IOSR Journal of Environmental Science, Toxicology and Food 
Technology (IOSR-JESTFT): Volume 8, (9), PP 22-30.

23. Zemichael G., Mulat G., Zinabu T., \& Mesafint M., (2014): Assessment of occupational injury and associated factors among municipal solid waste management workers in Gondar town and Bahir Dar City, northwest Ethiopia, Journal of Medicine and Medical Sciences Vol. 5(9) pp. 181-192.

24. Zerihun E., Meaza G., Tesfaye Y., Lemma D., \& Antehun A., (2017): Assessment of respiratory symptoms and associated factors among solid waste collectors in Yeka Sub City, Addis Ababa, Ethiopia, Vol. 9(6), pp. 189-197. 